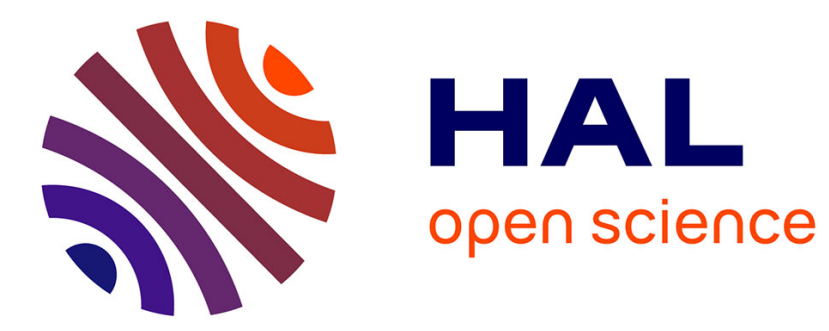

\title{
Satellite cells deficiency and defective regeneration in dynamin 2-related centronuclear myopathy
}

\author{
Camila F Almeida, Marc Bitoun, Mariz Vainzof
}

\section{To cite this version:}

Camila F Almeida, Marc Bitoun, Mariz Vainzof. Satellite cells deficiency and defective regeneration in dynamin 2-related centronuclear myopathy. FASEB Journal, 2021, 35 (4), pp.e21346. 10.1096/fj.202001313rrr . hal-03448321

\section{HAL Id: hal-03448321 \\ https://hal.science/hal-03448321}

Submitted on 21 Dec 2021

HAL is a multi-disciplinary open access archive for the deposit and dissemination of scientific research documents, whether they are published or not. The documents may come from teaching and research institutions in France or abroad, or from public or private research centers.
L'archive ouverte pluridisciplinaire HAL, est destinée au dépôt et à la diffusion de documents scientifiques de niveau recherche, publiés ou non, émanant des établissements d'enseignement et de recherche français ou étrangers, des laboratoires publics ou privés. 
Satellite cells deficiency and defective regeneration in dynamin2-related centronuclear myopathy

Camila F. Almeida, ${ }^{1,2,}$, Marc Bitoun ${ }^{2}$, Mariz Vainzof ${ }^{1}$

${ }^{1}$ Laboratory of Muscle Proteins and Comparative Histopathology, Human Genome and Stem Cell Research Center, Biosciences Institute, University of São Paulo, São Paulo, Brazil

${ }^{2}$ Sorbonne Université, INSERM, Institute of Myology, Centre of Research in Myology, UMRS 974, F75013, Paris, France

*Present address: Center for Gene Therapy, Nationwide Children's Hospital, Columbus, OH, USA;

Departments of Pediatrics, The Ohio State University, Columbus, OH, USA.

Corresponding author:

Dr. Mariz Vainzof

Human Genome and Stem Cell Research Center, IBUSP

Rua do Matão, 106 - Cidade Universitária

São Paulo, SP - CEP 05508-900. Brazil

PHONE: +55 $113091-7736$

FAX: +55 $113091-0852$

e-mail: mvainzof@usp.br

Running title: Muscle regeneration in dominant centronuclear myopathy 
Nonstandard Abbreviations

AD-CNM - autosomal dominant centronuclear myopathy

CTX - cardiotoxin

dMyHC - developmental myosin heavy chain

EI - electric induced

SC - satellite cell 


\begin{abstract}
Dynamin 2 (DNM2) is a ubiquitously expressed protein involved in many functions related to trafficking and remodeling of membranes and cytoskeleton dynamics. Mutations in the DNM2 gene cause the autosomal dominant centronuclear myopathy (AD-CNM), characterized mainly by muscle weakness and central nuclei. Several defects have been identified in the KI-Dnm2 $2^{\mathrm{R} 465 \mathrm{~W} /+}$ mouse model of the disease to explain the muscle phenotype, including reduction of satellite cells pool in muscle, but the functional consequences of this depletion have not been characterized until now. Satellite cells (SC) are the main source for muscle growth and regeneration of mature tissue. Here, we investigated muscle regeneration in the $\mathrm{KI}-D n m 2^{\mathrm{R} 465 \mathrm{~W} /+}$ mouse model for AD-CNM. We found a reduced number of Pax7positive SCs, which were also less activated after induced muscle injury. The muscles of the KIDnm $2^{\mathrm{R} 465 \mathrm{~W} /+}$ mouse regenerated more slowly and less efficiently than wild-type ones, formed fewer new myofibers, and did not recover its normal mass 15 days after injury. Altogether, our data provide evidence that the muscle regeneration is impaired in the $\mathrm{KI}-\mathrm{Dnm} 2^{\mathrm{R} 465 \mathrm{~W} /+}$ mouse and contribute with one more layer to the comprehension of the disease, by identifying a new pathomechanism linked to DNM2 mutations which may be involved in the muscle-specific impact occurring in AD-CNM.
\end{abstract}

Key words: congenital, GTPase, stem cell, muscle, injury 


\section{Introduction}

Centronuclear myopathies (CNM) form a group of rare congenital myopathies, clinically and genetically heterogeneous, characterized mainly by muscle weakness. Mutations in several genes have been identified as the cause of X-linked, autosomal recessive, and autosomal dominant forms of inheritance, but mutations in $M T M 1, B I N 1$, and DNM2 genes represent most of the reported cases (1-3). Clinical signals in CNMs vary from severe hypotonia in newborns to milder muscle weakness in patients with early-adulthood onset. The main histological feature is the high incidence of centrally positioned nuclei in muscle fibers (4).

The autosomal dominant centronuclear myopathy (AD-CNM) is due to mutations in the dynamin 2 gene (DNM2) (1), leading to a wide clinical spectrum. Neonatal cases are characterized by severe hypotonia, generalized weakness, facial weakness, ptosis, and ophthalmoplegia (5). Late-childhood or adult-onset patients present delayed motor milestones, diffuse muscle weakness mainly affecting limbs and face, accompanied by ptosis and ophthalmoplegia $(6,7)$. In the majority of adult cases, the disease progresses slowly, with normal cardiac and respiratory functions (6). Histologically, AD-CNM is characterized by predominance and atrophy of type I fibers, centralized nuclei, and radiating sarcoplasmic strands (8). More than 20 different DNM2 mutations have been found as causative of ADCNM (9), and some specific mutations are also associated with Charcot-Marie-Tooth neuropathy (10) and hereditary spastic paraplegia (11).

The ubiquitously expressed dynamin 2 belongs to the family of large GTPases (12) that participates in various membrane-remodeling processes throughout the cell and trafficking events, including clathrin-independent and dependent endocytosis, intracellular membrane trafficking, microtubule and actin networks dynamics $(12,13)$. In membrane trafficking events, DNM2 oligomers form a helical structure around the neck of the nascent vesicle, and GTP hydrolysis leads to vesicle release in the cytoplasm (14). Dynamin 2 mRNA and protein expression are normally expressed in ADCNM patients $(1,15)$, while protein localization may be altered, with cytosolic accumulation in DNM2 mutant models $(16,17)$. The most frequent DNM2 mutation (p.R465W), found in $30 \%$ of patients, was used to develop the knock-in mouse model KI-Dnm $2^{\mathrm{R} 465 \mathrm{~W} /+}$. This model develops a phenotype similar to human patients, characterized by a progressive myopathy with impairment of contractile properties, muscle atrophy, and structural disorganization but without nuclear centralization. This model has helped to reveal many mechanisms behind AD-CNM. Heterozygous (HTZ) mice present impaired actindependent trafficking (18), alterations in calcium homeostasis (19), perturbation of excitation-contraction 
coupling (20), and desmin network disorganization (21), which can explain the contractile properties alterations. Atrophy may develop as a result of impairment of autophagy and the recent finding of a low number and altered distribution of nuclei in the muscle fibers (22). Recently, a reduced number of satellite cells was demonstrated in the tibialis anterior muscle from $\mathrm{KI}-\mathrm{Dnm} 2^{\mathrm{R} 465 \mathrm{~W} /+}$ mice (22). Among other functions, satellite cells (SC) are resident stem cells of muscle providing a source for nuclei during adult muscle regeneration (23). Here, we aim at investigating the regenerative capacity of an adult and nonatrophied muscle from KI-Dnm2 $2^{\mathrm{R} 465 \mathrm{~W} /+}$ mice.

\section{Materials and Methods}

\section{Animals}

The knock-in Dnm2 $2^{\mathrm{R} 465 \mathrm{~W} /+}$ mouse line (hereafter referred to as KI-Dnm2 or HTZ) was established as previously described (16). Animals were housed under controlled light and temperature conditions, with water and food ad libitum. Five heterozygous (HTZ) and five wild-type (WT) littermates were used as uninjured controls. Eight HTZ (corresponding to $n=8$ independent samples) and eight WT individuals were included in electrical-induced injury experiments per time point, except for time points 5-days and 15-days in which seven HTZ and WT were used. Three animals per group were used for the cardiotoxin

injection experiment. All animals were three-month-old to investigate regeneration in an adult muscle and males to avoid sex-related responses. All procedures were performed under isoflurane anesthesia, according to French guidelines. Animal studies conform to the French laws and regulations concerning the use of animals for research and were approved by an external Ethical committee (approval no. 00351.02 delivered by the French Ministry of Higher Education and Scientific Research).

\section{Muscle injury}

To induce muscle degeneration, we used two different techniques. The first one is based on the methodology for electroporation of the muscle, using an electrical shock-induced injury protocol (24). Briefly, the hairs from the calves were removed and the electrodes pads were positioned perpendicularly to muscle fibers orientation, in the center of the muscles, at equal distances from the knee and the ankle. The muscles were injured by applying eight electrical pulses at an intensity of 100 Volts, during 20 milliseconds each pulse, separated by a 0.5 -second interval delivered using an electroporation device 
(ECM830, Electro Square Porator, Harvard Apparatus, Holliston, MA, USA). The second injury procedure was done by cardiotoxin injection (25). We injected $150 \mu \mathrm{L}$ of $10 \mu \mathrm{M}$ cardiotoxin solution percutaneously (Cardiotoxin, Naja pallida, 217503, Merck, Molsheim, Alsace, France) in both gastrocnemius muscles, in the center of the muscles, at equal distances from the knee and the ankle. Animals were euthanized by cervical dislocation three, five, ten, and fifteen days post-lesion. For each mouse, one muscle was used for histological analysis, and the contralateral muscle was used for molecular analysis.

\section{Histopathology}

Gastrocnemius muscles were harvested and immediately frozen in liquid nitrogen-cooled isopentane. The muscles were cut in $6 \mu \mathrm{m}$ cryosections in the portion at equal distance between the knee and the ankle, where the electrodes were positioned and the cardiotoxin was injected. To evaluate histological alterations, the sections were stained with hematoxylin-eosin (HE) as follows: staining for 10 minutes in hematoxylin solution, rinsing in running tap water for 10 minutes, followed by staining in eosin solution for three minutes, and rinsing in running tap water. The muscle sections were fixed in acetic acid and dehydrated in ethanol and xylol. Sirius red staining was performed to quantify collagen deposition. First, slides were fixed in Bouin solution for 20 minutes and rinsed in tap water. Next, the sections were stained in Sirius red solution $(0.2 \mathrm{~g}$ Sirius red in $100 \mathrm{~mL}$ aqueous picric acid) for one hour, followed by dehydration in ethanol and xylol. HE and Sirius red slides were mounted with mounting medium. Slides were visualized on a conventional upright microscope (Axio Imager.Z1, Carl Zeiss, Oberkochen, Germany), with a Zeiss EC Plan-Neofluar 40X/0.5 $/ 0.17$ objective, without polarized light. Images were captured with an AxioCam HRm camera and Axion Vision Software (Carl Zeiss). HE images were adjusted for color balance. The presence of necrosis, degeneration, infiltrating cells, and centronucleation was qualitatively described. The percentages indicated in Table 1 refer to the whole sections of each muscle observed. Quantification of Sirius red staining was done on five different random fields of muscle section using ImageJ software.

\section{Immunohistochemistry}


Muscle cryosections were labeled with primary antibodies including rabbit anti-laminin (1:300 dilution, Z0097, Dako), mouse anti-developmental myosin heavy chain (dMyHC) (1:30, NCL-MHCd, NovoCastra, Buffalo Grove, IL, USA), anti-Ki67 (1:200, ab5580, Abcam, Cambridge, MA) and mouse anti-PAX7 (1:20, concentrate, Developmental Studies Hybridoma Bank, Iowa, IA, USA), overnight at $4^{\circ} \mathrm{C}$. Secondary antibodies were anti-rabbit AlexaFluor ${ }^{\circledR} 488$ (1:100, A-11008, Thermo Fisher Scientific, Waltham, MA, USA), anti-mouse Cy3 (1:100, C2181, Sigma Aldrich, St. Louis, MO, USA) or AlexaFluor ${ }^{\circledR} 568$ (1:100, A-11004, Thermo Fisher Scientific). Secondary antibodies were incubated 1 hour and sections were counterstained with DAPI diluted in mounting medium Vectashield®) (Vector Laboratories, Burlingame, CA, USA). The sections were visualized on a Carl Zeiss (LSM800) confocal microscope with a Zeiss EC Plan-Neofluar 20X/0.5 $\infty / 0.17$ objective, and images captured with LSM800 MA-Pmt2 device and ZenBlue software, and on conventional fluorescence microscope Axion Imager.Z1 with Axion Vision Software (Carl Zeiss). For PAX7 and Ki67 staining, muscle sections were submitted to antigen retrieval with hot citric acid and blocked with mouse IgG Fab fragment (1:100, Jackson Immuno Research, West Grove, PA, USA) before immunostaining. Whole muscle sections imaging was performed in the Nikon Eclipse Ti2 microscope, with a Nikon Plan Apo 20X/0.75 $\infty / 0.17$ objective. Counting of dMyHC-positive fibers, Ki67-positive, and PAX7-positive nuclei were done manually, using the plugin Cell Counter of ImageJ software. dMyHC-positive fibers were counted in muscle sections of eight EI-injured animals per genotype, and three CTX-injured animals per genotype. We counted from five to eight different fields randomly selected. Ki67-positive nuclei were counted in 30 random fields of muscle sections of five individuals per genotype, five days after EI. PAX7-positive nuclei were counted in whole muscle sections of five non-injured animals of each genotype. The total number of fibers was calculated in a semi-automated fashion in QuPath software (26). Fiber's diameter was measured on laminin stained sections, using ImageJ software, according to Treat-NMD guidelines (SOP DMD_M.1.2.001).

\section{RNA extraction, cDNA synthesis, and $q P C R$}

Total RNA was extracted from whole muscle using the RNeasy Microarray Tissue Mini Kit (Qiagen, Germantown, MD, USA) following the manufacturer's instructions. Quantity and quality of RNA were assessed with Nanodrop 8000 Spectrophotometer (Thermo Fisher Scientific) and 1\% agarose gel electrophoresis to verify the integrity of $18 \mathrm{~S}$ and $28 \mathrm{~S}$ bands. We used only samples with an 
A260/A280 ratio between 1.7 and 2.1. To obtain cDNA, $1 \mu \mathrm{g}$ of RNA was reverse transcribed using SuperScript VILO Mastermix (Thermo Fisher Scientific) according to the manufacturer's instructions.

For qPCR, specific primers were designed for each gene of interest, and Tbp was used as the endogenous control. Primers sequences: Myf5 Fw-CTG TCT GGT CCC GAA GAA C, Rv- GAC GTG ATC CGA TCC ACA ATG; $M y o d$ Fw-TAC AGT GGC GAC TCA GAT GC, Rv-TAG TAG GCG GTG TCG TAG CC; Myog Fw-CTG CAC TCC CTT ACG TCC AT, Rv-CCC AGC CTG ACA GAC AAT CT; Pax7 Fw-GAG TTC GAT TAG CCG AGT GC, Rv-GTG TTT GGC TTT CTT CTC GC; Spryl FwGGT CAT AGG TCA GAT CGG GTC, Rv-CTT GCC ACA CTG TTC GCA G; Tbp Fw-TGC ACA GGA GCC AAG AGT GAA, Rv-CAC ATC ACA GCT CCC CAC CA. Amplification was done with SybrGreen Master Mix (Roche, Basel, Switzerland). The run was performed in 7500 Applied Biosystems thermocycler. Results were analyzed with 7500 Software v2.0.6. Relative expression of the target genes was calculated as mean values of $2^{-\Delta \Delta \mathrm{CT}}$.

\section{Statistical analysis}

Graphs and statistical analyses were done in GraphPad Prism software version 5.00. Data are presented as the mean \pm standard deviation (SD). Differences between any two groups were assessed using Mann-Whitney test. Differences between multiple groups were tested with Kruskal-Wallis test followed by Dunn's multiple comparison test. Only significant differences are shown in the graphs. A value of $\mathrm{p}<0.05$ was considered statistically significant.

\section{Results}

\section{Pax7 expression and Pax7-positive cells number are reduced in gastrocnemius of HTZ mice}

In order to identify whether there is a reduction of satellite cells content in the adult and nonatrophied muscles from HTZ KI-Dnm2 mice, we first analyzed the expression of Pax7 mRNA in the gastrocnemius muscle of three-month-old animals. We found a decrease of $70 \%$ in $\operatorname{Pax} 7$ expression $(\mathrm{p}=0.0079)$ as compared to the WT control by quantitative real-time PCR (Figure 1A). Next, we immunostained muscle sections for Pax7 (Figure 1C) and counted the number of Pax7-positive (Pax7+) nuclei in relation to the total number of fibers (Figure 1B). The counting revealed a value of 16 satellite 
cells per 100 fibers in WT gastrocnemius muscle which is reduced by 50\% in HTZ muscle in the same range that decreased Pax7 expression. This confirms recent findings gained in Tibialis anterior muscle (22) and establishes gastrocnemius muscle from HTZ mice as a proper model for investigating the regenerative capacity of adult muscle in this AD-CNM mouse model.

\section{Muscle mass of HTZ mice did not recover after acute lesion}

To assess muscle regeneration in a CNM context, we provoked muscle injury in WT and HTZ mice by electrical shock (electric-induced, EI) as recently validated for gastrocnemius (27) and cardiotoxin (CTX) injection. We then measured the absolute mass of gastrocnemius and relative mass by total body weight after three, five, ten, and fifteen days. Although the Feret's diameter of uninjured muscles from HTZ is slightly reduced in comparison to WT, WT and HTZ showed no significant differences in the gastrocnemius mass or gastrocnemius/body weight ratio (Figure 2A-D), indicating that the muscle phenotype was initiated, but not to the extent to impact the muscle mass. After EI lesion, the gastrocnemius mass of WT animals decreased slightly, with a significant reduction after 5 and 10 days, but it returned to normal levels after 15 days. For HTZ the reduction was substantial and muscle mass did not recover after 15 days (Figure 2A). After CTX injury, the same pattern of muscle mass reduction was detected (Figure 2B).

The fiber size, quantified through measurement of the minimal Feret's diameter, was smaller at day 15 after EI and CTX injuries in WT gastrocnemius muscle (Figure 2E and 2F) reflecting that normal size was not fully restored 15 days post-injury. Consequently, the fiber density (number of fibers per area) increased in WT muscle after EI and CTX (Figure 2G and 2H). In HTZ muscle, a similar decrease in fiber size occurred after injury (Figure $2 \mathrm{E}$ and $2 \mathrm{~F}$ ) but without an increase in fiber density (Figure 2G and $2 \mathrm{H}$ ) suggesting a defect in the number of the newly formed fibers and/or an increased area of interstitial tissue. HTZ fibers had their diameter already reduced compared to WT before lesion (Figure $2 \mathrm{E}$ and $2 \mathrm{~F}$ ) whereas muscle mass was similar to WT (0d in Figure 2A-D) and the mean size is still smaller in HTZ mice $(28.9 \mu \mathrm{m})$ than in WT $(33.2 \mu \mathrm{m})$ after EI and CTX injury (Figure 2E and 2F). Altogether these results showed that the p.R465W-DNM2 mutation alters the regenerative capacity of muscle leading to reduced muscle mass recovery 15 days post-injury. 


\section{Histopathology following muscle injury}

H\&E staining was performed at each time point to follow the course of the regeneration in HTZ and WT muscle (Figure 3). Regardless of the injury method, regeneration occurred in similar ways in WT mice, featured by a peak of necrosis and degeneration, identified by a pale color in HE staining, and infiltration of inflammatory cells invading muscle followed by restoration by new fibers formation appearing at day 3 (Figure 3 and Table 1). After 15 days, WT muscles regenerated completely evidenced by fibers of normal appearance containing centrally positioned nuclei. HTZ muscles presented the same features but with a still ongoing degenerative process, with the presence of many infiltrating cells after 5 days. At this point, we noted the first regenerating fibers in HTZ muscles. Ten days post-injury, HTZ muscles had some remaining necrotic areas, especially in CTX injury. After 15 days, HTZ muscles were regenerated, but the new fibers appeared smaller with larger central nuclei.

Next, we assessed the transient deposition of interstitial tissue during regeneration as an index of proper regenerative process using collagens staining by Sirius Red. We observed that interstitial tissue was slightly increased 15 days post-injury in WT muscle (Figure 4) ( +30\%). HTZ muscles exhibited a higher collagen content compared to WT in basal conditions $(\sim+20 \%)$ and the increase induced by injury was exacerbated $(\sim+40 \%)$. Overall, time course and post-lesion histopathological features argue for a slower and less efficient regeneration in muscle harboring a Dnm2 mutation.

\section{Decreased formation of new myofibers}

We next sought to precisely evaluate the time course of formation of new fibers by the expression of developmental myosin heavy chain, because it is a myosin isoform transiently expressed by recently formed and immature fibers during muscle regeneration (Figure 5) (28). For EI and CTX induced injury, the first $\mathrm{dMyHC}$-positive fibers were observed after three days and the last $\mathrm{dMyHC}$-positive fibers disappeared before 10 days post-injury in WT muscle with a peak at day 5 (Figure 5). The time course of dMyHC expression was similar after EI for the HTZ muscle although around 5\% of fibers were still positive after 10 days (Figure 5B and 5C) suggestive of a slowed down regenerative process. Muscles injected with cardiotoxin revealed a shift between WT and HTZ muscles (Figure 5D and 5E). At three days post-CTX, only $1 \%$ of fiber was found positive for $\mathrm{dMyHC}$, and $5 \%$ of $\mathrm{HTZ}$ fibers maintained positive staining after 10 days. Besides, the number of newly formed fibers at the peak was significantly reduced (only $30 \%$ for HTZ compared to $70 \%$ for WT, p=0.1 using a Mann-Whitney test). Overall, this 
analysis suggests that regeneration is delayed in HTZ muscles which are forming fewer new myofibers to repair the lesion.

\section{HTZ mice have less activated satellite cells after injury}

After activation in response to an injury, SCs proliferate intensely to repair the tissue. Hence, we sought to assess whether SC proliferation may be also affected in KI-Dnm2 mice. A well-known marker of the proliferative activity is Ki67 (29). Thus, we labeled EI-injured muscles with Ki67 and PAX7 antibodies to identify the actively proliferating SCs (Figure 6A). Compared to data from figure 1 in uninjured muscle, EI induced an increase in the total number of Pax7+ cells in WT muscle, reaching around 60 Pax7+ cells per 100 fibers (Figure 6C). Among this pool of cells, $40 \%$ were positive for Ki67 (Figure 6B). In regenerated HTZ muscle, the number of Pax7+cells remained lower compared to WT (Figure 6C) and only 25\% of this reduced pool of Pax7+ cells were also positive for Ki67 (Figure 6B). Altogether, our data show that Dnm2 mutation affects the two main characteristics of SC required for proper regeneration, i.e. their number in steady-state and after regeneration and their proliferative capacity in response to muscle injury.

\section{Overall downregulation of myogenic regulatory factors}

Because of the satellite cell deficiency and impaired regeneration in HTZ muscles, we analyzed the activation of genes related to the regeneration pathway by measuring expression of myogenic regulatory factors (MRFs) and genes important for SC regulation before and after lesion (30) to obtain an indirect measurement of satellite cell population dynamics during regeneration. In WT muscle submitted to EI and CTX injury, expression of Pax7, Myf5, Myod, and Myog transiently increased during regeneration with a peak at day 3 for Myod and at day 5 for Pax7, Myf5, and Myog (Figure 7). Inversely, Spryl expression transiently decreased during regeneration in WT muscle with a minimum reached at day 3 as expected (31). Under uninjured condition (day 0), HTZ muscle showed significant down expression of Pax7 and Myf5, overexpression of Myog and Spryl, and similar expression of Myod when compared to WT uninjured muscle showing that gene expression was not only determined by reduction of the number of satellite cells. In HTZ mice, Pax7, Myf5, Myod, and Myog also activated after injury but at lower levels when compared to WT muscles at a same time point. Spryl expression was reduced 
three days after injury and a subsequent increase occurred as the regeneration proceeded, like in WT muscle, but reaching lower expression level compared to WT in spite of a higher baseline a day 0 . In summary, we detected alterations in the expression of myogenic factors not strictly correlated to the reduced number of SC suggesting that the genetic program of the SCs may be compromised in HTZ mice.

\section{Discussion}

Skeletal muscle has a remarkable regenerative capacity that relies mainly on the muscle-specific stem cells called satellite cells (32-34). In this work, we sought to investigate muscle regeneration in a mouse model of dynamin 2-linked dominant centronuclear myopathy. We found a significantly small number of $\mathrm{SC}$ in the gastrocnemius muscle of $\mathrm{KI}-D n m 2^{\mathrm{R} 465 \mathrm{~W}}$ mouse associated with an altered regeneration, evidenced by a reduced level of proliferating SCs and regenerating fibers, altered expression of genes related to the myogenic program, loss of mass of regenerated muscle, and interstitial tissue deposition.

\section{Steady-state in uninjured HTZ muscle}

Impairment in the SC population has been documented in various neuromuscular disorders as an important component of disease development (35-41). In particular, a reduced number of satellite cells have been previously identified in the X-linked form of centronuclear myopathy, also called Myotubular myopathy, due to mutation in myotubularin (42). We demonstrate a similar reduction in the number of SCs in the gastrocnemius muscle of an AD-CNM animal model, confirming the recent results gained in the tibialis anterior muscle of this model (22) and suggesting a potential common mechanism for the centronuclear myopathies. The cause of SC depletion is not clear in centronuclear myopathies. In diseases marked by chronic degeneration, SCs are constantly activated, leading to their depletion and impaired regeneration $(40,43)$. It seems not to be the case for AD-CNM regarding the absence of signs of chronic degeneration in muscle biopsies from patients (4) confirmed by absence of dMyHC-positive fibers and central nuclei in uninjured muscles from HTZ KI-Dnm2 mice. Reduction of Pax7 expression may trigger loss of SC as demonstrated in $\mathrm{Pax}^{-/-}$knock out mice (44), probably through coordination of expression of genes related to cell proliferation, and repression of genes of terminal muscle 
differentiation (45). The baseline of expression of other genes related to the regeneration pathway is also impaired in uninjured HTZ muscle. If the downregulation of Pax7 and Myf5 may be partially attributed to the depletion of the SC pool, overexpression of Myog and Spryl may reflect deregulation of the genetic program related to SC regulation. In particular, the increased expression of Spryl, which is an important regulator of myoblast quiescence $(31,46)$, could impose a constraint to maintain quiescence, delaying SC activation when necessary. Altogether, reduction of SC pool and deregulation of gene expression associated with slight fibrotic deposition, also evidenced in uninjured HTZ muscle, may compose nonpermissive conditions to a proper injury-induced regeneration.

\section{Muscle regeneration in HTZ mice}

Different protocols of muscle injury are available that can be grouped according to the agent employed: physical, chemical, or toxins. Despite all these methods being able to provoke an acute muscle degeneration followed by regeneration, they are not completely identical and it is documented important differences among them (47). Such differences can mask or unveil important data, as shown in an investigation of the regeneration in $M y f 5$-null mice, in which a specific role of $M y f 5$ was only revealed by the freeze-injury method (48). In consequence, we sought to examine muscle regeneration in HTZ KI-Dnm2 mice using two distinct acute injury procedures provoked by either electrical shock or cardiotoxin injection.

In WT mice, electrical shock or cardiotoxin injection are followed by muscle regeneration leading to rapid muscle mass recovery in 15 days post-injury. During this period, regeneration appears delayed or defective in HTZ KI-Dnm2 mice. Besides the reduction in the SC population, our main finding is the smaller proportion of Pax7-positive cells in active proliferation. It may hypothesize that synergy of these two defects results in an insufficient number of cells available for muscle repair explaining a slower or delayed regeneration, as evidenced by histological analysis and shift in the timing of emergence of dMyHC-positive fibers. This may also lead to reduced or absent transient injury-induced regulation of genes involved in SC regulation and defective regeneration suggested by the formation of fewer fibers and increased fibrotic deposition in the 15 days following injury and no recovery of muscle mass. After activation of SCs, Spryl is downregulated in proliferating Pax7+ cells, and to be able to return to quiescence, a fraction of SCs resumes Spryl expression after some rounds of division (31, 46). Consistently, we observed a downregulation of Spryl following injury, and progressive upregulation 
suggesting that the HTZ SCs do not have restrictions in returning to quiescence. However, an examination of the polarity of the dividing Pax7-positive satellite cells would be required to better characterize stem-cell renewal. Overall, our results strongly suggest that, although the regeneration is properly activated, a delayed and defective muscle regeneration occurs in the KI-Dnm2 mouse model.

\section{Implication for dominant centronuclear myopathy}

Several alterations in SCs behavior have been described in different forms of myopathies including the $\mathrm{X}$-linked form of centronuclear myopathy in which a reduced number and delayed proliferation of satellite cells have been previously identified (42). In many cases, a reduction in the number of SCs, accompanied by defective proliferation, differentiation, and thus regeneration has been observed in patients with neuromuscular disorders. Such alterations in the number and function of SC are often considered as a consequence of the disease instead of a primary mechanism. Interestingly, a myopathy caused by a mutation in the $P A X 7$ gene was recently described leading to SC exhaustion (38) similar to the phenotype of the Pax7 knock-out mouse model (44). The patients carrying biallelic PAX7 variants present a clinical phenotype including hypotonia, ptosis, and muscular atrophy but without affecting muscle fiber stability, all features also present in patients affected by centronuclear myopathies. This suggests that, even though we cannot consider defective satellite cell population as a primary causative aspect of centronuclear myopathies, the clinical phenotype associated with SC dysfunction may participate in a significant part of phenotype encountering in CNM patients. Further investigation will be necessary to determine how DNM2 mutations impact SC number and function. It was shown that the GTPase activity of dynamin 2 is required in later stages of myoblasts membrane fusion (49). However, we recently excluded an impact on fusion during differentiation by showing normal fusion index in myoblasts cultured from KI-Dnm2 neonates compared to WT littermates (22). In order to better understand the impact of DNM2 mutation on muscle regeneration, investigation whether regenerated fibers are re-innervated normally at a single motor endplate region, or potential impact on other nonmyogenic tissues required for proper regeneration will be required. Nevertheless, our work highlights the importance to take into account SC impairments in the development of future therapies which will need to also target SC to optimize their efficiency.

In conclusion, our study represents the first arguments for abnormal muscle regeneration which may results from the dysfunction of satellite cells in dominant centronuclear myopathy. Given that 
satellite cells (SC) are also involved in muscle post-natal growth, exercise dependent muscle hypertrophy, and muscle maintenance during different life stages $(50,51)$, even in aging (52), the impact of SC function in AD-CNM may be much more diverse than the muscle regeneration. Taken together, our results suggest that albeit all the molecular pathways are activated for muscle regeneration, the overall outcome is compromised in HTZ animals and this is probably due to the reduction of the satellite cells pool in steady-state and a defect of their proliferative capacity upon injury. Overall, our results identify a new pathomechanism of Dynamin 2-linked CNM which may be involved in the muscle-specific impact of DNM2 mutations characterizing the disease.

\section{Acknowledgments}

The authors would like to thank the scientific and technical support of the team from the Human Genome and Stem Cell Research Center of the University of São Paulo, São Paulo, Brazil. We also thank the research team from the Institute of Myology, Centre of Research in Myology, Paris, France. This work was supported by Conselho Nacional de Desenvolvimento Científico e Tecnológico (CNPq grant 456522/2014-0), Fundação de Amparo à Pesquisa do Estado de São Paulo - Centro de Pesquisa, Inovação e Difusão (FAPESP-CEPID grants 2013/08028-1, 2015/18914-4, and 2017/07376-7), and Financiadora de Estudos e Projetos (FINEP grant 01.08.0579.00).

\section{Author contributions}

C. F. Almeida, M. Bitoun, and M. Vainzof designed research; C. F. Almeida and M. Bitoun performed research; C. F. Almeida analyzed data; C. F. Almeida, M. Bitoun and M. Vainzof wrote the paper.

\section{References}

1. Bitoun, M., Maugenre, S., Jeannet, P. Y., Lacène, E., Ferrer, X., Laforêt, P., Martin, J. J., Laporte, J., Lochmüller, H., Beggs, A. H., Fardeau, M., Eymard, B., Romero, N. B., and Guicheney, P. (2005) Mutations in dynamin 2 cause dominant centronuclear myopathy. Nat Genet 37, 12071209

2. Laporte, J., Hu, L. J., Kretz, C., Mandel, J. L., Kioschis, P., Coy, J. F., Klauck, S. M., Poustka, A., and Dahl, N. (1996) A gene mutated in X-linked myotubular myopathy defines a new putative tyrosine phosphatase family conserved in yeast. Nature Genetics 13, 175-182

3. Nicot, A. S., Toussaint, A., Tosch, V., Kretz, C., Wallgren-Pettersson, C., Iwarsson, E., Kingston, H., Garnier, J. M., Biancalana, V., Oldfors, A., Mandel, J. L., and Laporte, J. (2007) Mutations in 
amphiphysin 2 (BIN1) disrupt interaction with dynamin 2 and cause autosomal recessive centronuclear myopathy. Nature Genetics 39, 1134-1139

4. Romero, N. B. and Bitoun, M. (2011) Centronuclear myopathies. Seminars in Pediatric Neurology 18, 250-256

5. Bitoun, M., Bevilacqua, J. A., Prudhon, B., Maugenre, S., Taratuto, A. L., Monges, S., Lubieniecki, F., Cances, C., Uro-Coste, E., Mayer, M., Fardeau, M., Romero, N. B., and Guicheney, P. (2007) Dynamin 2 mutations cause sporadic centronuclear myopathy with neonatal onset. Annals of Neurology 62, 666-670

6. Fischer, D., Herasse, M., Bitoun, M., Barragán-Campos, H. M., Chiras, J., Laforêt, P., Fardeau, M., Eymard, B., Guicheney, P., and Romero, N. B. (2006) Characterization of the muscle involvement in dynamin 2-related centronuclear myopathy. Brain 129, 1463-1469

7. Hanisch, F., Müller, T., Dietz, A., Bitoun, M., Kress, W., Weis, J., Stoltenburg, G., and Zierz, S. (2011) Phenotype variability and histopathological findings in centronuclear myopathy due to DNM2 mutations. Journal of Neurology 258, 1085-1090

8. Sewry, C. A. and Wallgren-Pettersson, C. (2017) Myopathology in congenital myopathies. Neuropathology and Applied Neurobiology 43, 5-23

9. Böhm, J., Biancalana, V., DeChene, E. T., Bitoun, M., Pierson, C. R., Schaefer, E., Karasoy, H., Dempsey, M. A., Klein, F., Dondaine, N., Kretz, C., Haumesser, N., Poirson, C., Toussaint, A., Greenleaf, R. S., Barger, M. A., Mahoney, L. J., Kang, P. B., Zanoteli, E., Vissing, J., Witting, N., Echaniz-Laguna, A., Wallgren-Pettersson, C., Dowling, J., Merlini, L., Oldfors, A., Ousager, L. B., Melki, J., Krause, A., Jern, C., Oliveira, A. S. B., Petit, F., Jacquette, A., Chaussenot, A., Mowat, D., Leheup, B., Cristofano, M., Aldea, J. J. P., Michel, F., Furby, A., Llona, J. E. B., van Coster, R., Bertini, E., Urtizberea, J. A., Drouin-Garraud, V., roud, C. B., Prudhon, B., Bedford, M., Mathews, K., Erby, L. A. H., Smith, S. A., Roggenbuck, J., Crowe, C. A., Spitale, A. B., Johal, S. C., Amato, A. A., Demmer, L. A., Jonas, J., Darras, B. T., Bird, T. D., Laurino, M., Welt, S. I., Trotter, C., Guicheney, P., Das, S., Mandel, J. L., Beggs, A. H., and Laporte, J. (2012) Mutation spectrum in the large gtpase dynamin 2, and genotype-phenotype correlation in autosomal dominant centronuclear myopathy. Human Mutation 33, 949-959

10. Sidiropoulos, P. N. M., Miehe, M., Bock, T., Tinelli, E., Oertli, C. I., Kuner, R., Meijer, D., Wollscheid, B., Niemann, A., and Suter, U. (2012) Dynamin 2 mutations in Charcot-Marie-Tooth neuropathy highlight the importance of clathrin-mediated endocytosis in myelination. Brain 135, 1395-1411

11. Sambuughin, N., Goldfarb, L. G., Sivtseva, T. M., Davydova, T. K., Vladimirtsev, V. A., Osakovskiy, V. L., Danilova, A. P., Nikitina, R. S., Ylakhova, A. N., Diachkovskaya, M. P., Sundborger, A. C., Renwick, N. M., Platonov, F. A., Hinshaw, J. E., and Toro, C. (2015) Adultonset autosomal dominant spastic paraplegia linked to a GTPase-effector domain mutation of dynamin 2. BMC Neurology 15

12. Ferguson, S. M. and de Camilli, P. (2012) Dynamin, a membrane-remodelling GTPase. Nat Rev Mol Cell Biol 13, 75-88 
13. Durieux, A. C., Prudhon, B., Guicheney, P., and Bitoun, M. (2010) Dynamin 2 and human diseases. Journal of Molecular Medicine 88, 339-350

14. Warnock, D. E., Baba, T., and Schmid, S. L. (1997) Ubiquitously expressed dynamin-II has a higher intrinsic GTPase activity and a greater propensity for self-assembly than neuronal dynaminI. Mol Biol Cell 8, 2553-2562

15. Bitoun, M., Durieux, A. C., Prudhon, B., Bevilacqua, J. A., Herledan, A., Sakanyan, V., Urtizberea, A., Cartier, L., Romero, N. B., and Guicheney, P. (2009) Dynamin 2 mutations associated with human diseases impair clathrin-mediated receptor endocytosis. Hum Mutat 30, 1419-1427

16. Durieux, A. C., Vignaud, A., Prudhon, B., Viou, M. T., Beuvin, M., Vassilopoulos, S., Fraysse, B., Ferry, A., Lainé, J., Romero, N. B., Guicheney, P., and Bitoun, M. (2010) A centronuclear myopathy-dynamin 2 mutation impairs skeletal muscle structure and function in mice. Human Molecular Genetics 19, 4820-4836

17. Kenniston, J. A. and Lemmon, M. A. (2010) Dynamin GTPase regulation is altered by PH domain mutations found in centronuclear myopathy patients. EMBO Journal 29, 3054-3067

18. González-Jamett, A. M., Baez-Matus, X., Olivares, M. J., Hinostroza, F., Guerra-Fernández, M. J., Vasquez-Navarrete, J., Bui, M. T., Guicheney, P., Romero, N. B., Bevilacqua, J. A., Bitoun, M., Caviedes, P., and Cárdenas, A. M. (2017) Dynamin-2 mutations linked to Centronuclear Myopathy impair actin-dependent trafficking in muscle cells. Scientific Reports 7, 4580

19. Fraysse, B., Guicheney, P., and Bitoun, M. (2016) Calcium homeostasis alterations in a mouse model of the Dynamin 2-related centronuclear myopathy. Biology Open 5, 1691-1696

20. Kutchukian, C., Szentesi, P., Allard, B., Trochet, D., Beuvin, M., Berthier, C., Tourneur, Y., Guicheney, P., Csernoch, L., Bitoun, M., and Jacquemond, V. (2017) Impaired excitationcontraction coupling in muscle fibres from the dynamin2R $465 \mathrm{~W}$ mouse model of centronuclear myopathy. Journal of Physiology 595, 7369-7382

21. Franck, A., Lainé, J., Moulay, G., Lemerle, E., Trichet, M., Gentil, C., Benkhelifa-Ziyyat, S., Lacène, E., Bui, M. T., Brochier, G., Guicheney, P., Romero, N., Bitoun, M., and Vassilopoulos, S. (2019) Clathrin plaques and associated actin anchor intermediate filaments in skeletal muscle. Molecular Biology of the Cell 30, 579-590

22. Fongy, A., Falcone, S., Lainé, J., Prudhon, B., Martins-Bach, A., and Bitoun, M. (2019) Nuclear defects in skeletal muscle from a Dynamin 2-linked centronuclear myopathy mouse model. Scientific Reports 9

23. Almeida, C. F., Fernandes, S. A., Ribeiro Junior, A. F., Keith Okamoto, O., and Vainzof, M. (2016) Muscle satellite cells: Exploring the basic biology to rule them. Stem Cells International 2016

24. Almeida, C. F. and Vainzof, M. (2020) Skeletal Muscle Injury by Electroporation: A Model to Study Degeneration/Regeneration Pathways in Muscle. In Methods in Molecular Biology vol. 2063, pp. 157-169, Humana Press Inc. 
25. Garry, G. A., Antony, M. L., and Garry, D. J. (2016) Cardiotoxin induced injury and skeletal muscle regeneration. Methods in Molecular Biology 1460, 61-71

26. Bankhead, P., Loughrey, M. B., Fernández, J. A., Dombrowski, Y., McArt, D. G., Dunne, P. D., McQuaid, S., Gray, R. T., Murray, L. J., Coleman, H. G., James, J. A., Salto-Tellez, M., and Hamilton, P. W. (2017) QuPath: Open source software for digital pathology image analysis. Scientific Reports 7

27. Almeida, C. F. and Vainzof, M. (2020) Skeletal Muscle Injury by Electroporation: A Model to Study Degeneration/Regeneration Pathways in Muscle. In Methods in Molecular Biology vol. 2063, pp. 157-169, Humana Press Inc.

28. Schiaffino, S., Rossi, A. C., Smerdu, V., Leinwand, L. A., and Reggiani, C. (2015) Developmental myosins: Expression patterns and functional significance. Skeletal Muscle 5, 1-14

29. Rose, D. S. C., Maddox, P. H., and Brown, D. C. (1994) Which proliferation markers for routine immunohistology? A comparison of five antibodies. Journal of Clinical Pathology 47, 1010-1014

30. Zammit, P. S. (2017) Function of the myogenic regulatory factors Myf5, MyoD, Myogenin and MRF4 in skeletal muscle, satellite cells and regenerative myogenesis. Seminars in Cell \& Developmental Biology 72, 19-32

31. Shea, K. L., Xiang, W., LaPorta, V. S., Licht, J. D., Keller, C., Basson, M. A., and Brack, A. S. (2010) Sprouty1 regulates reversible quiescence of a self-renewing adult muscle stem cell pool during regeneration. Cell Stem Cell 6, 117-129

32. Lepper, C., Partridge, T. A., and Fan, C.-M. (2011) An absolute requirement for Pax7-positive satellite cells in acute injury-induced skeletal muscle regeneration. Development 138, 3639-3646

33. Sambasivan, R., Yao, R., Kissenpfennig, A., Wittenberghe, L. van, Paldi, A., Gayraud-Morel, B., Guenou, H., Malissen, B., Tajbakhsh, S., and Galy, A. (2011) Pax7-expressing satellite cells are indispensable for adult skeletal muscle regeneration. Development 138, 3647-3656

34. Murphy, M. M., Lawson, J. A., Mathew, S. J., Hutcheson, D. A., and Kardon, G. (2011) Satellite cells, connective tissue fibroblasts and their interactions are crucial for muscle regeneration. Development 138, 3625-3637

35. Castets, P., Bertrand, A. T., Beuvin, M., Ferry, A., le Grand, F., Castets, M., Chazot, G., Rederstorff, M., Krol, A., Lescure, A., Romero, N. B., Guicheney, P., and Allamand, V. (2011) Satellite cell loss and impaired muscle regeneration in selenoprotein $\mathrm{N}$ deficiency. Human Molecular Genetics 20, 694-704

36. Kudryashova, E., Kramerova, I., and Spencer, M. J. (2012) Satellite cell senescence underlies myopathy in a mouse model of limb-girdle muscular dystrophy 2H. J Clin Invest 122, 1764-1776

37. Ross, J., Benn, A., Jonuschies, J., Boldrin, L., Muntoni, F., Hewitt, J. E., Brown, S. C., and Morgan, J. E. (2012) Defects in glycosylation impair satellite stem cell function and niche composition in the muscles of the dystrophic Large(myd) mouse. Stem Cells 30, 2330-2341

38. Feichtinger, R. G., Mucha, B. E., Hengel, H., Orfi, Z., Makowski, C., Dort, J., D’Anjou, G., Nguyen, T. T. M., Buchert, R., Juenger, H., Freisinger, P., Baumeister, S., Schoser, B., Ahting, 
U., Keimer, R., Nguyen, C. T. E., Fabre, P., Gauthier, J., Miguet, M., Lopes, F., AlHakeem, A., AlHashem, A., Tabarki, B., Kandaswamy, K. K., Bauer, P., Steinbacher, P., Prokisch, H., Sturm, M., Strom, T. M., Ellezam, B., Mayr, J. A., Schöls, L., Michaud, J. L., Campeau, P. M., Haack, T. B., and Dumont, N. A. (2019) Biallelic variants in the transcription factor PAX7 are a new genetic cause of myopathy. Genetics in Medicine 21, 2521-2531

39. Dumont, N. A., Wang, Y. X., von Maltzahn, J., Pasut, A., Bentzinger, C. F., Brun, C. E., and Rudnicki, M. A. (2015) Dystrophin expression in muscle stem cells regulates their polarity and asymmetric division. Nat Med 21, 1455-1463

40. Heslop, L., Morgan, J. E., and Partridge, T. A. (2000) Evidence for a myogenic stem cell that is exhausted in dystrophic muscle. Journal of Cell Science 113, 2299-2308

41. Ribeiro, A. F., Souza, L. S., Almeida, C. F., Ishiba, R., Fernandes, S. A., Guerrieri, D. A., Santos, A. L. F., Onofre-Oliveira, P. C. G., and Vainzof, M. (2019) Muscle satellite cells and impaired late stage regeneration in different murine models for muscular dystrophies. Scientific Reports 9

42. Lawlor, M. W., Alexander, M. S., Viola, M. G., Meng, H., Joubert, R., Gupta, V., Motohashi, N., Manfready, R. A., Hsu, C. P., Huang, P., Buj-Bello, A., Kunkel, L. M., Beggs, A. H., and Gussoni, E. (2012) Myotubularin-deficient myoblasts display increased apoptosis, delayed proliferation, and poor cell engraftment. American Journal of Pathology 181, 961-968

43. Sacco, A., Mourkioti, F., Tran, R., Choi, J., Llewellyn, M., Kraft, P., Shkreli, M., Delp, S., Pomerantz, J. H., Artandi, S. E., and Blau, H. M. (2010) Short telomeres and stem cell exhaustion model Duchenne muscular dystrophy in mdx/mTR mice. Cell 143, 1059-1071

44. Oustanina, S., Hause, G., and Braun, T. (2004) Pax7 directs postnatal renewal and propagation of myogenic satellite cells but not their specification. EMBO Journal 23, 3430-3439

45. Soleimani, V. D., Punch, V. G., Kawabe, Y. ichi, Jones, A. E., Palidwor, G. A., Porter, C. J., Cross, J. W., Carvajal, J. J., Kockx, C. E. M., van IJcken, W. F. J., Perkins, T. J., Rigby, P. W. J., Grosveld, F., and Rudnicki, M. A. (2012) Transcriptional Dominance of Pax7 in Adult Myogenesis Is Due to High-Affinity Recognition of Homeodomain Motifs. Developmental Cell 22, 1208-1220

46. Abou-Khalil, R. and Brack, A. S. (2010) Muscle stem cells and reversible quiescence: The role of sprouty. Cell Cycle 9, 2575-2580

47. Hardy, D., Besnard, A., Latil, M., Jouvion, G., Briand, D., Thépenier, C., Pascal, Q., Guguin, A., Gayraud-Morel, B., Cavaillon, J. M., Tajbakhsh, S., Rocheteau, P., and Chrétien, F. (2016) Comparative Study of Injury Models for Studying Muscle Regeneration in Mice. PloS one 11, e0147198

48. Gayraud-Morel, B., Chrétien, F., Flamant, P., Gomès, D., Zammit, P. S., and Tajbakhsh, S. (2007) A role for the myogenic determination gene Myf5 in adult regenerative myogenesis. Developmental Biology 312, 13-28

49. Leikina, E., Melikov, K., Sanyal, S., Verma, S. K., Eun, B., Gebert, C., Pfeifer, K., Lizunov, V. A., Kozlov, M. M., and Chernomordik, L. v. (2013) Extracellular annexins and dynamin are important for sequential steps in myoblast fusion. Journal of Cell Biology 200, 109-123 
50. Bachman, J. F., Klose, A., Liu, W., Paris, N. D., Blanc, R. S., Schmalz, M., Knapp, E., and Chakkalakal, J. v. (2018) Prepubertal skeletal muscle growth requires Pax7-expressing satellite cell-derived myonuclear contribution. Development 145, dev167197

51. Schultz, E. (1996) Satellite cell proliferative compartments in growing skeletal muscles. Developmental Biology 175, 84-94

52. Keefe, A. C., Lawson, J. A., Flygare, S. D., Fox, Z. D., Colasanto, M. P., Mathew, S. J., Yandell, M., and Kardon, G. (2015) Muscle stem cells contribute to myofibres in sedentary adult mice. Nature Communications 6

\section{Legends of Figures}

Figure 1. PAX7 deficiency in HTZ KI-Dnm2 muscle. A. Pax7 mRNA expression in HTZ and WT muscles. Relative expression was calculated by the $2^{-\Delta \Delta \mathrm{Ct}}$ method using WT average value as the normalizer sample. Mann-Whitney test, $n=5$ individuals per genotype, $* * p<0.01$. B. Quantification of the number of satellite cells, presented in relation to total fiber number in transverse cross-sections. Mann-Whitney test, $\mathrm{n}=6-7$ transversal sections from 3 animals of each genotype, $* * \mathrm{p}<0.01$. C. Representative images of PAX7 staining in WT and HTZ muscle sections. Laminin staining (green) was used to delimit fiber membrane; PAX7 stain in red indicated by white arrows. Scale bars $=50 \mu \mathrm{m}$.

Figure 2. Muscle mass, fiber diameter, and density are reduced after injury. A and C. Gastrocnemius mass relative to total body weight and gastrocnemius mass, respectively, after EI. MannWhitney test, $\mathrm{n}=5$ mice per genotype at time point zero, $\mathrm{n}=8$ mice per genotype at the other time points, except HTZ 5-days and WT 15-days, with n=7 each. B and D. Gastrocnemius mass relative to total body weight and gastrocnemius mass, respectively, after CTX. $n=5$ mice per genotype at time point zero, $n=3$ mice per genotype at the other time points. E. Feret's diameter of myofibers before and after EI injury. Kruskal-Wallis test followed by Dunn's multiple comparison test; $n=1278$ fibers in WT 0d, $n=1152$ fibers in HTZ 0d, n=2081 fibers in WT 15d and n=3291 fibers in HTZ 15d. F. Feret's diameter of myofibers before and after CTX injury. Kruskal-Wallis test followed by Dunn's multiple comparison test; $n=1278$ fibers in WT 0d, $n=1152$ fibers in HTZ 0d, $n=809$ fibers in WT 15d and $n=664$ fibers in HTZ 15d. G. Number of fibers per area (fiber density) after EI lesion. Mann-Whitney-test, $n=6-8$ transversal sections from 3 animals of each genotype/time point. H. Number of fibers per area (fiber density) after CTX injection. Mann-Whitney-test, $n=6$ transversal sections from 3 animals of each genotype/time point. Asterisks (*) denote differences in relation to WT at a similar time point, number 
sign (\#) in relation to HTZ at $0 \mathrm{~d}$. * and \# p<0.05, ** and \#\# p<0.01, *** and \#\#\# p<0.001, ns= nonsignificant.

Figure 3. Histopathology after EI and CTX lesion. Representative images of HE staining of muscles before and after injury. A. WT and HTZ muscles uninjured. B. Muscle necrosis is identified by pale fibers and infiltration of inflammatory cells. Regenerating fibers are visualized by five days post-lesion. At 15 days, muscle fibers are regenerated and have central nuclei. Scale bars $=100 \mu \mathrm{m}$ in A, and $50 \mu \mathrm{m}$ in $\mathrm{B}$.

Figure 4. Collagen staining and quantification in muscle from KI-Dnm2 mice after injury. A. Representative images of Sirius red staining in WT and HTZ muscles at days zero and 15. Scale bar=100 $\mu \mathrm{m}$. B. Quantification of Sirius red staining on muscles before (0d) and after (15d) EI. Mann-Whitney test, $* \mathrm{p}<0.05, * * \mathrm{p}<0.01, \mathrm{n}=5$ individuals for day zero, $\mathrm{n}=8$ individuals for day 15 .

Figure 5. Formation of new myofibers during regeneration after injury. New myofibers express developmental myosin heavy chain (in red). Membranes were delimited with laminin antibody (in green), nuclei were stained with DAPI (in blue). Arrows indicate dMyHC-positive fibers. Scale bar= $50 \mu \mathrm{m}$. A. WT and HTZ uninjured muscles. B. Formation of new myofibers after EI injury. C. Quantification of dMyHC-positive fibers in relation to the total number of fibers after EI lesion. $\mathrm{N}=5$ individuals per genotype at time point zero, $n=8$ individuals per genotype after lesion, except HTZ 5-days and WT 15days, with $\mathrm{n}=7$ each. D. Formation of new myofibers after CTX injection. E. Quantification of dMyHCpositive fibers in relation to the total number of fibers after CTX lesion. $\mathrm{N}=5$ individuals per genotype at time point zero, $\mathrm{n}=3$ individuals per genotype after lesion. In $\mathrm{C}$ and $\mathrm{E}$, five to seven random fields were manually counted per animal.

Figure 6. Proliferating satellite cells after 5 days of EI injury. A. Representative images of immunofluorescence staining of PAX7 (red) and Ki67 (green) proteins. Nuclei were stained with Dapi (blue). Scale bar $=50 \mu \mathrm{m}$. B. Percentage of Ki67+ and PAX7+ cells. C. Quantification of the number of satellite cells, presented in relation to total fiber number in transverse cross-sections. Mann-Whitney test, $\mathrm{n}=5$ animals per genotype, more than 1000 fibers were counted for each individual. $* * \mathrm{p}<0.01$.

Figure 7. Expression of myogenic regulatory genes in muscle from KI-Dnm2 mice after injury. Relative expression was measured by qRT-PCR before and during regeneration, and calculated by the $2^{-}$ ${ }^{\Delta \Delta \mathrm{Ct}}$ method. The values were normalized to WT uninjured. A. Expression of Pax7 mRNA after EI injury. B. Expression of Pax7 mRNA after CTX injury C. Expression of Myf5 mRNA after EI injury. D. 
Expression of Myf5 mRNA after CTX injury. E. Expression of Myod mRNA after EI injury. F. Expression of Myod mRNA after CTX injury. G. Expression of Myog mRNA after EI injury. H. Expression of Myog mRNA after CTX injury. I. Expression of Spry1 mRNA measured after EI lesion. J. Expression of Spry1 mRNA measured after CTX injury. In A to J, statistical analysis was done using Mann-Whitney test. For EI groups: $n=5$ mice per genotype at time point zero, $n=8$ mice per genotype after lesion, except HTZ 5-days and WT 15-days, with $n=7$ each. For CTX groups: $n=5$ mice per genotype for day zero, $\mathrm{n}=3$ mice per genotype after lesion. Asterisks (*) denote differences in relation to WT uninjured, number sign (\#) in relation to HTZ uninjured. * and $\# \mathrm{p}<0.05$, ** and \#\# $\mathrm{p}<0.01$, *** and \#\#\# p<0.001.

Table 1. Histological findings in EI and CTX injured muscles over time. - not detected; + up to 20\%; ++ between $20 \%$ and $50 \%$; +++ between $50 \%$ and $70 \%$; ++++ over $70 \%$ 
Figure 1

(A)

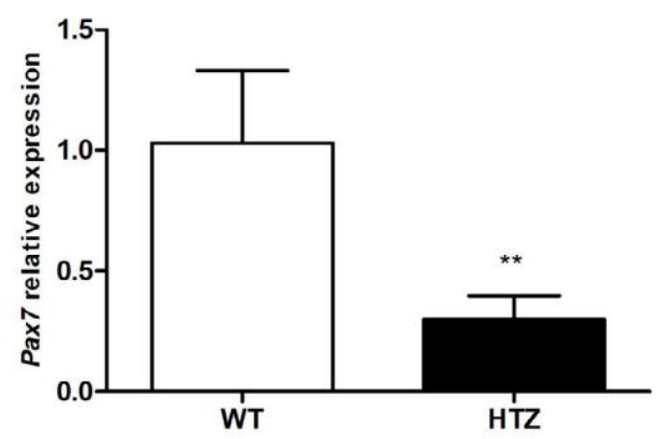

(C)
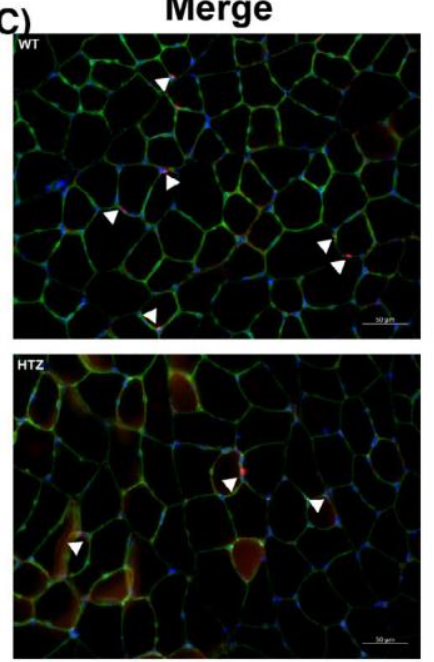

(B)
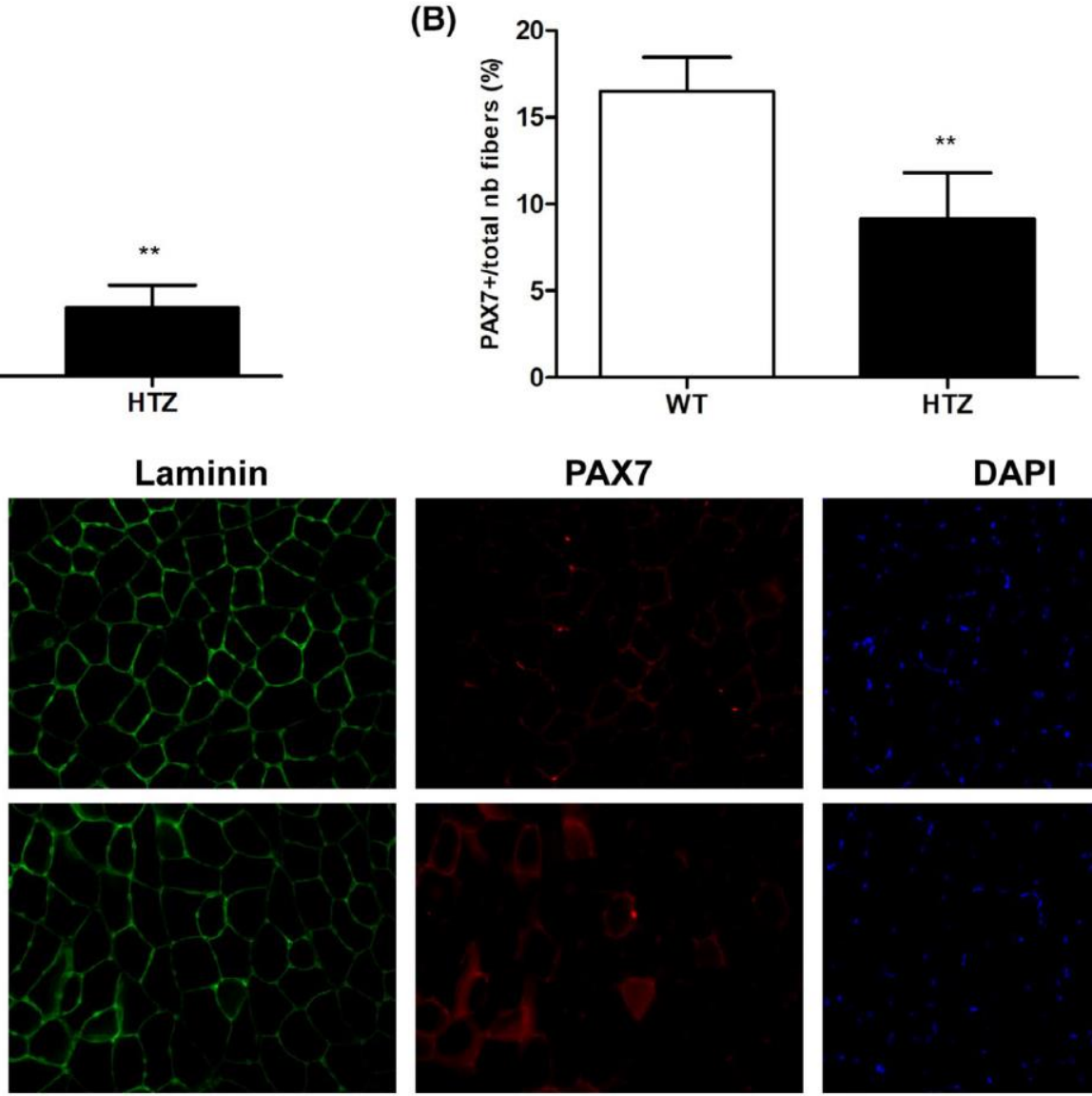

PAX7

DAPI
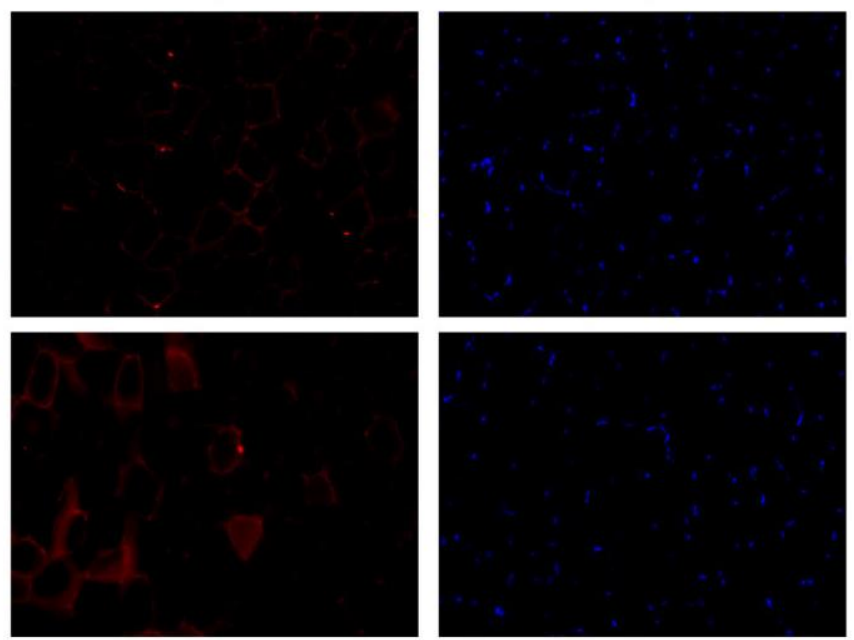
Figure 2

(A)

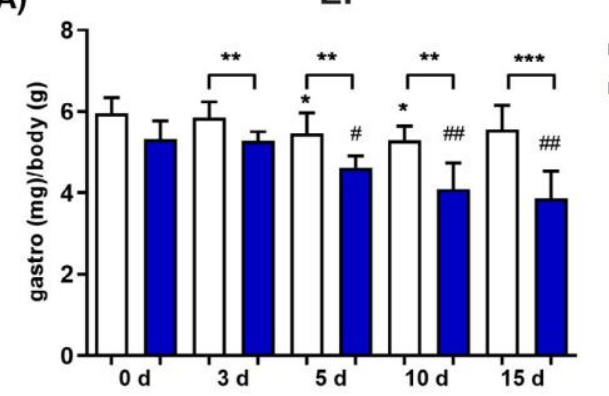

(C)

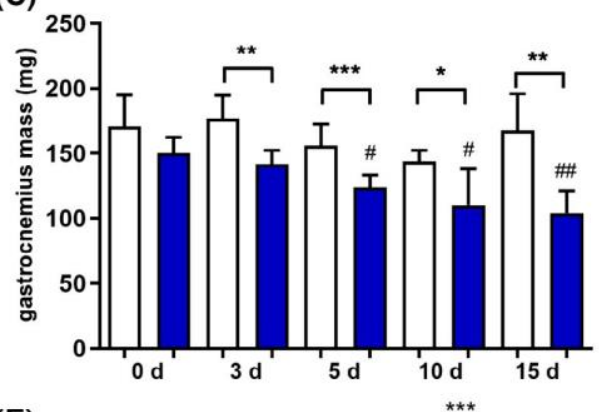

(E)

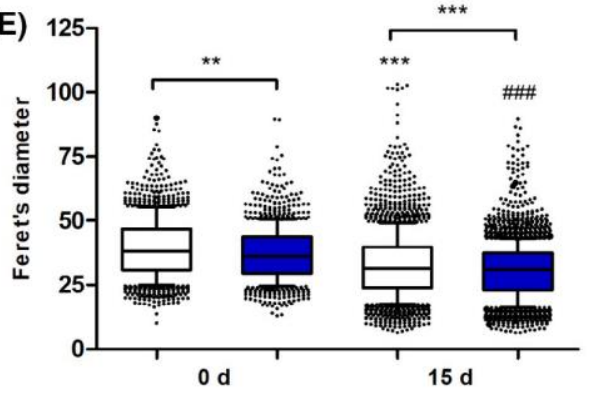

(G)

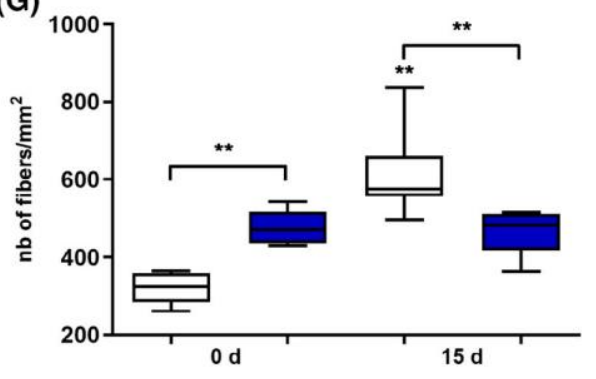

(B)

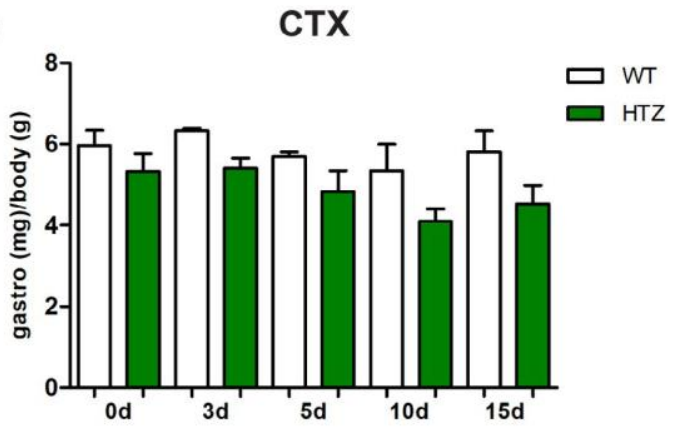

(D)

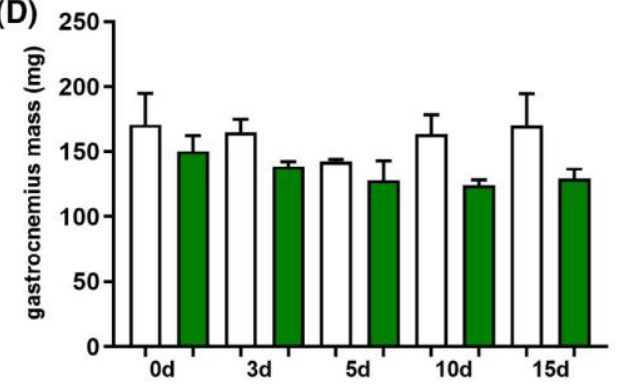

(F)

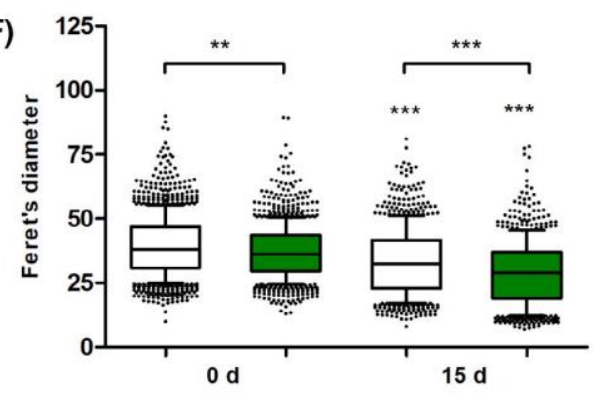

(H)

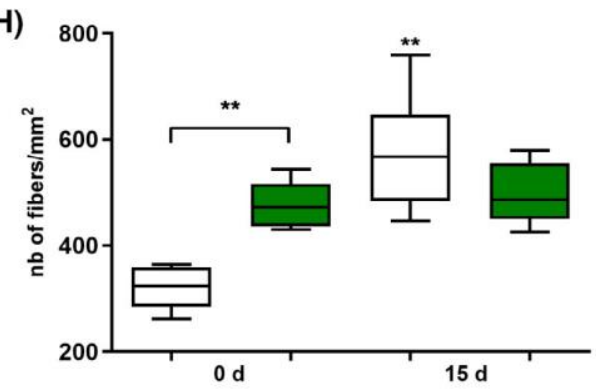


Figure 3
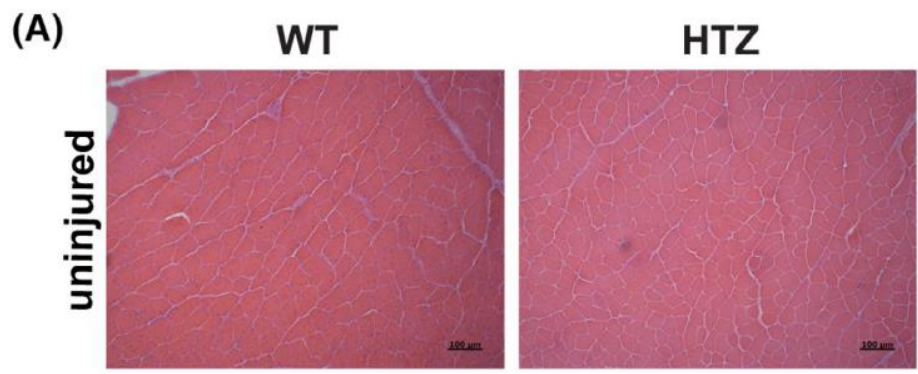

(B)
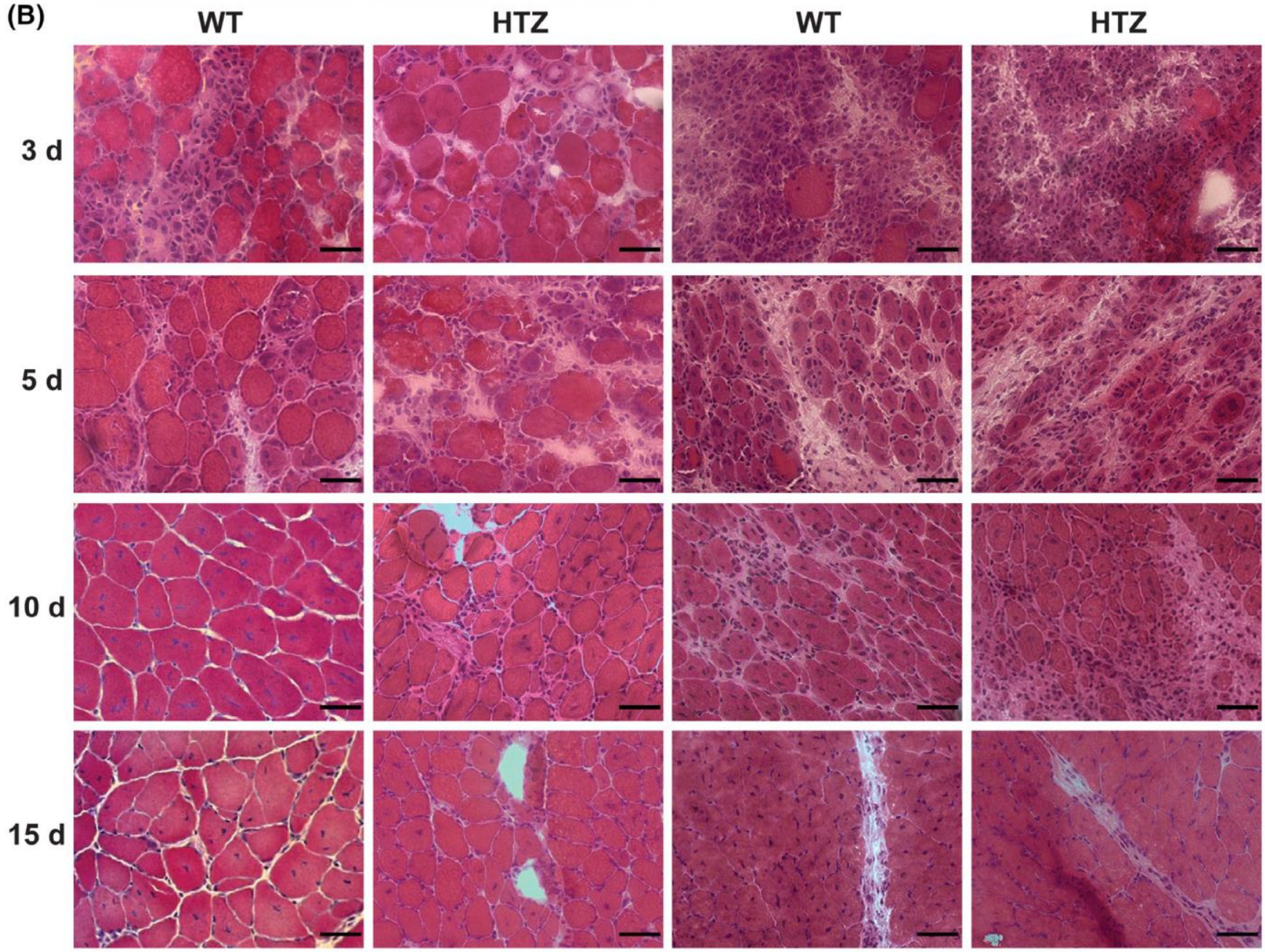

EI

CTX 

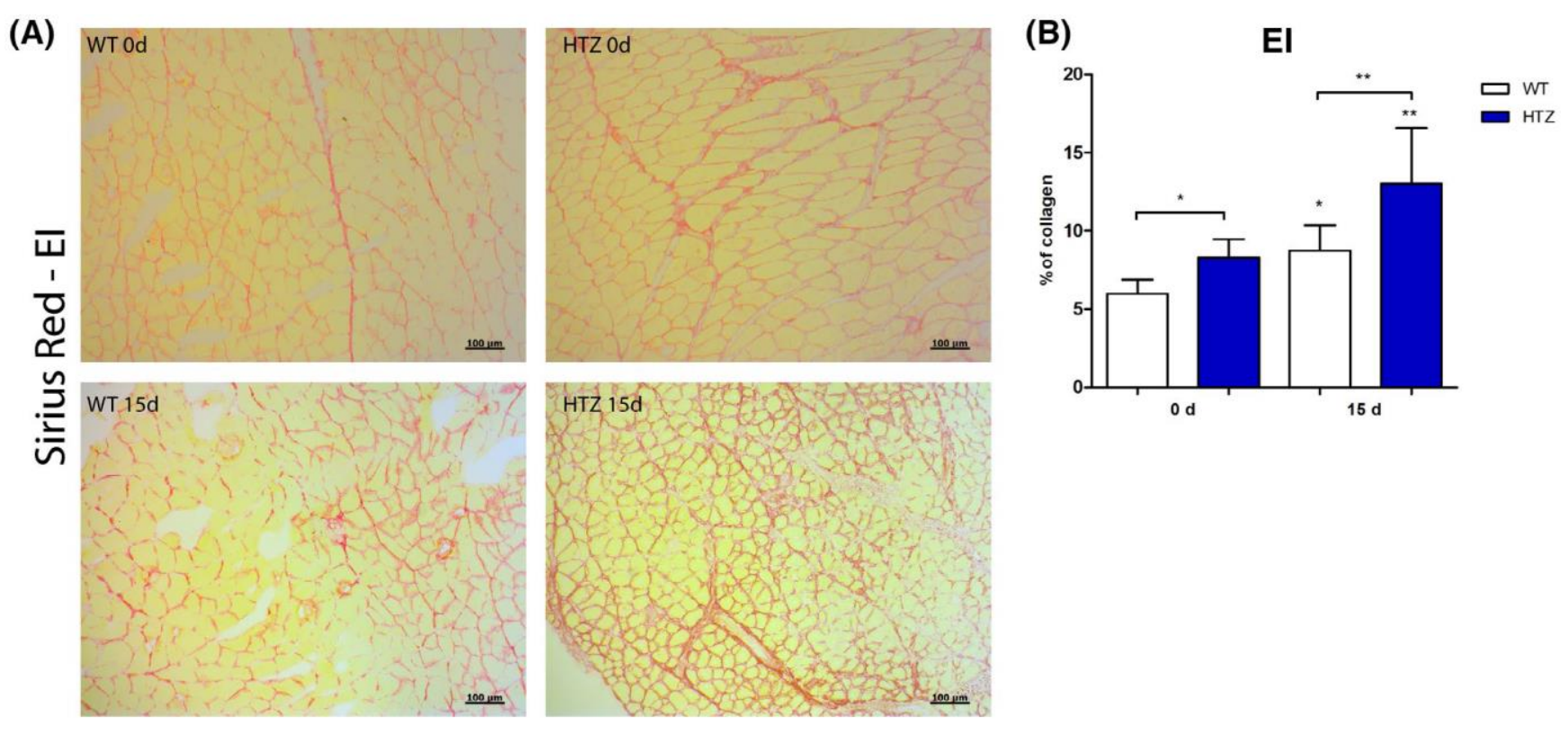
Figure 5

(A)

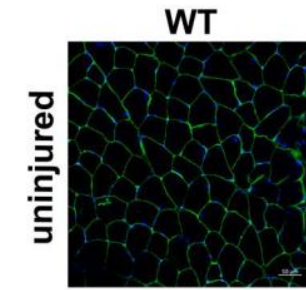

(B)

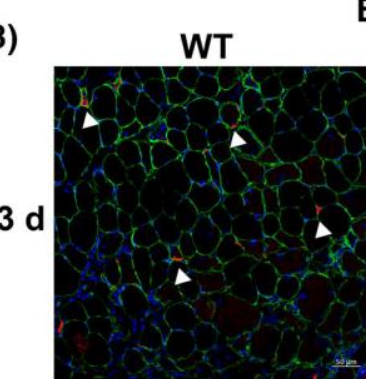

EI

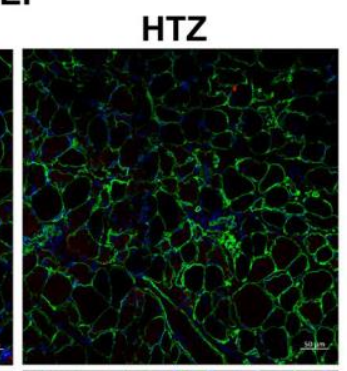

5 d

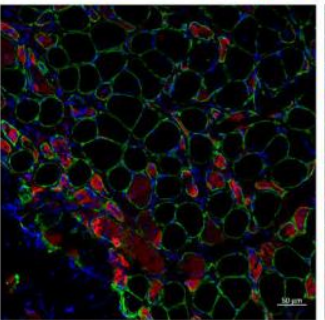

$10 \mathrm{~d}$
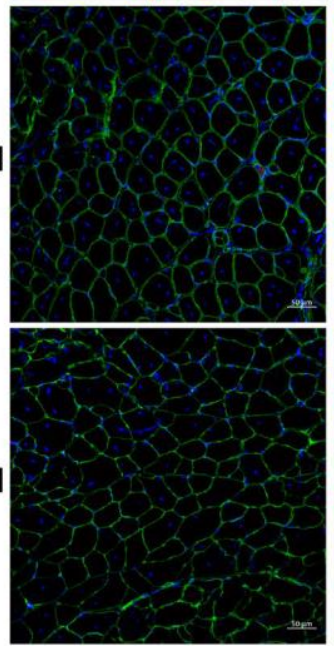

(C)

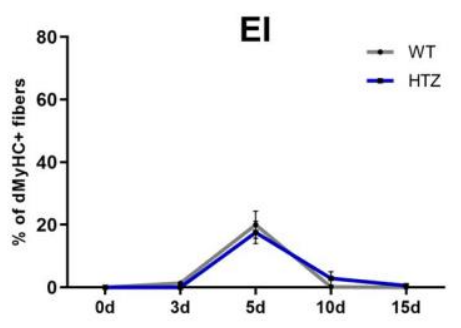

HTZ
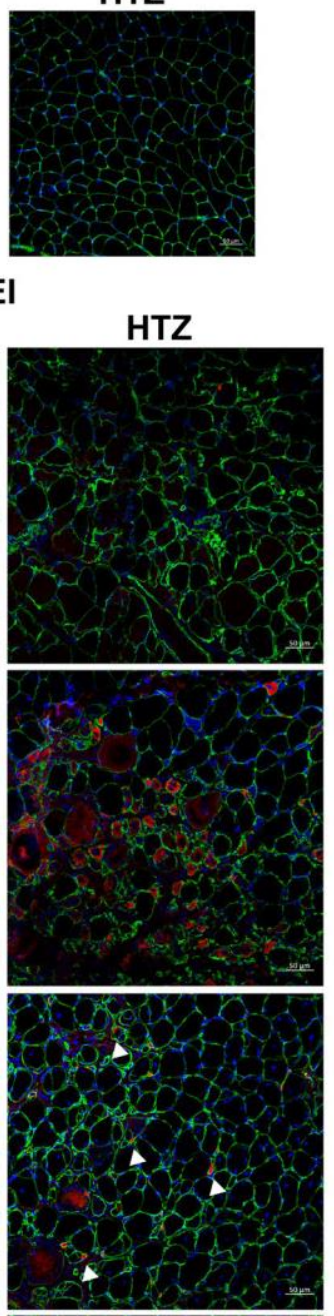

(D)

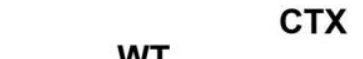

$3 \mathrm{~d}$

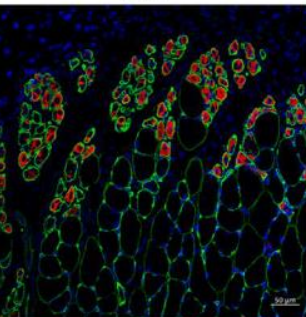

HTZ

$5 \mathrm{~d}$
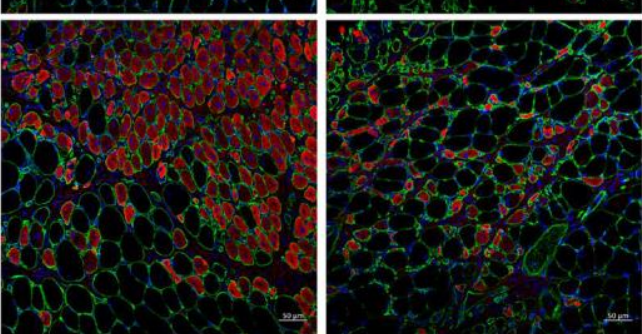

$10 \mathrm{~d}$

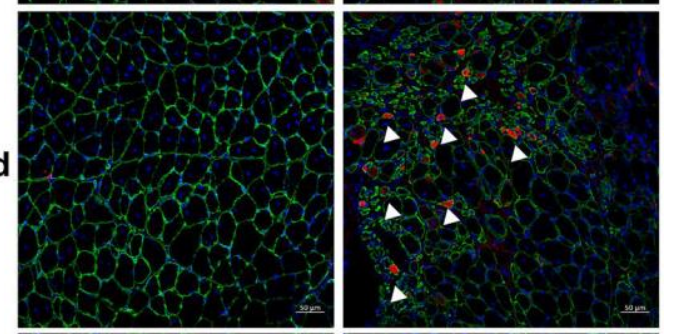

$15 \mathrm{~d}$

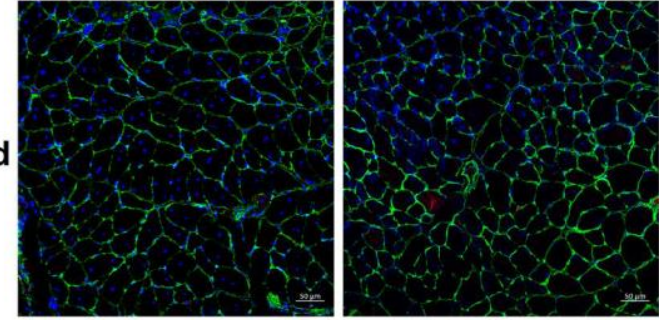

(E)

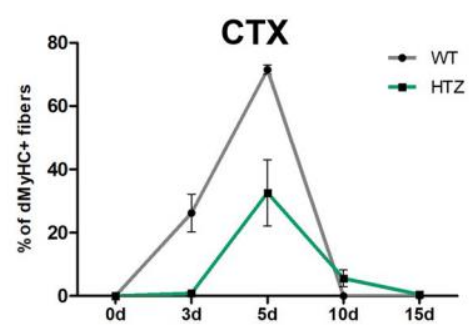


Figure 6

(A)
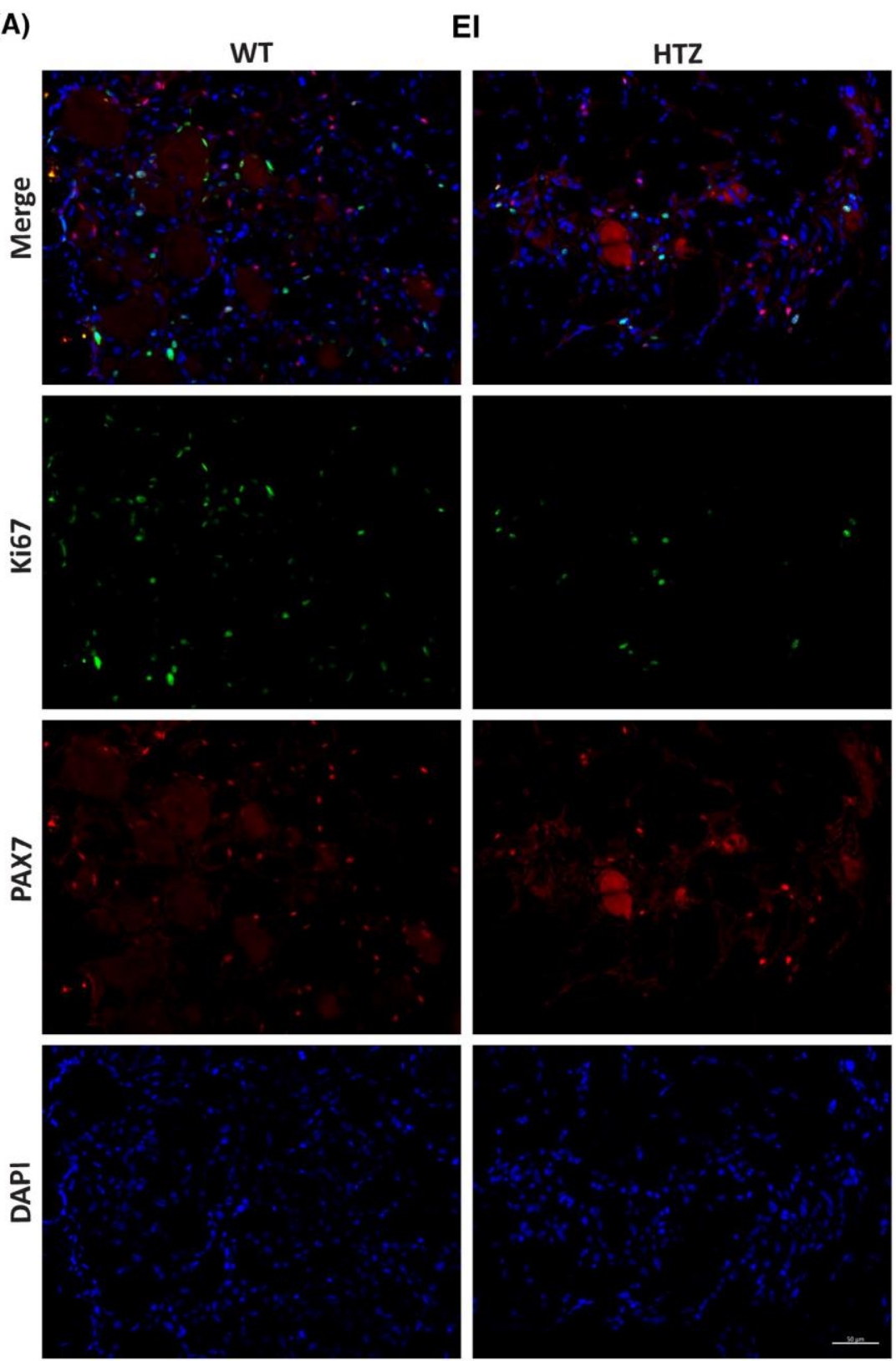

(B)

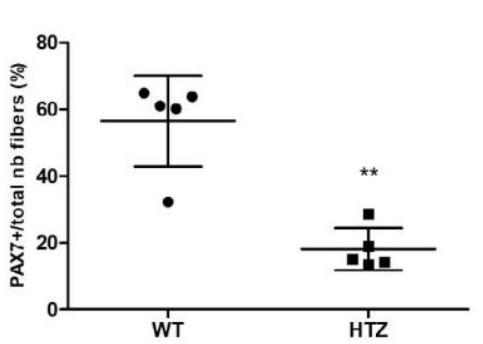

(C)

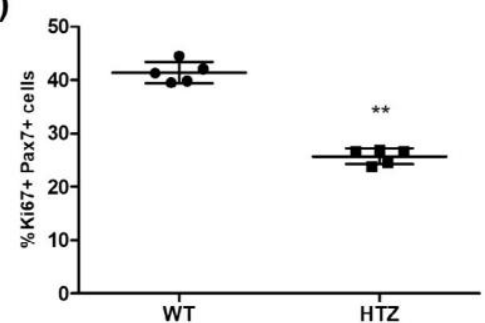


Figure 7

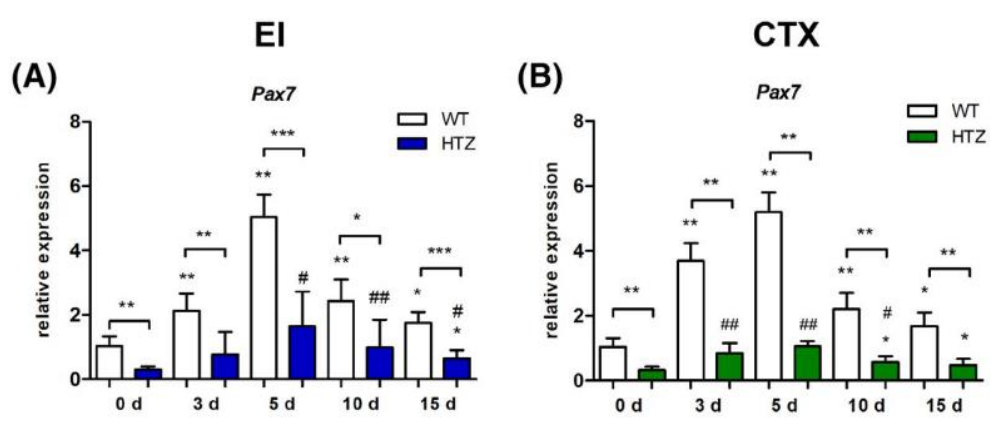

(C)

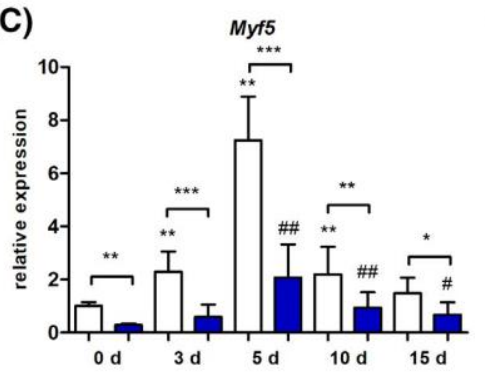

(E)
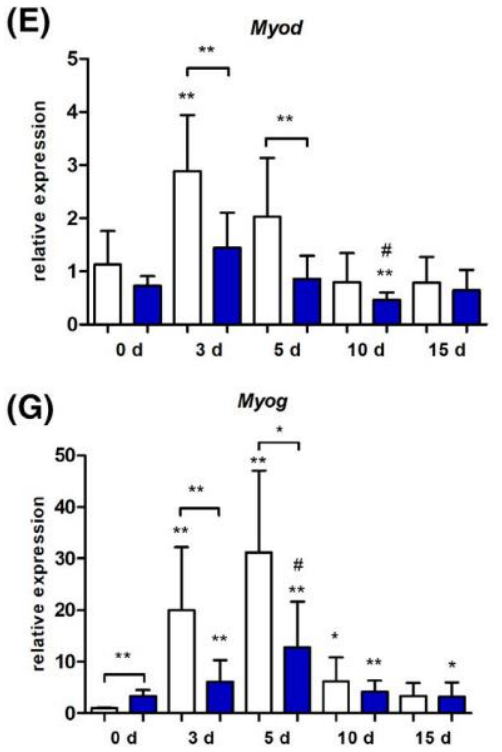

(I)

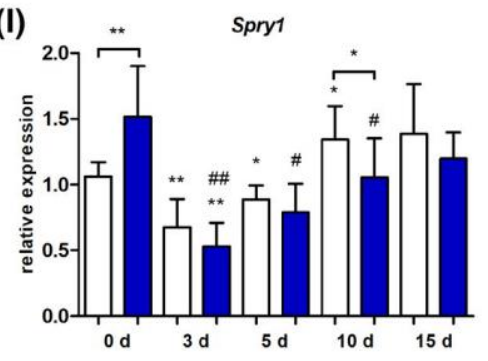

(D)

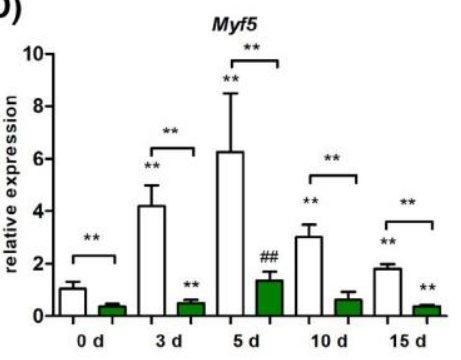

(F)

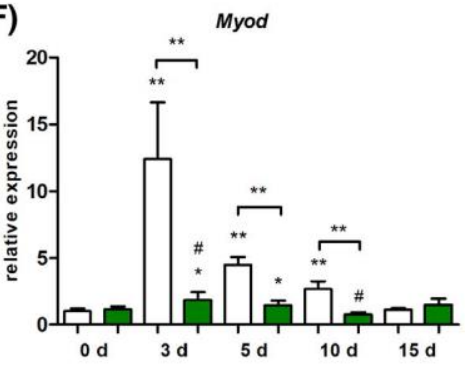

(H)
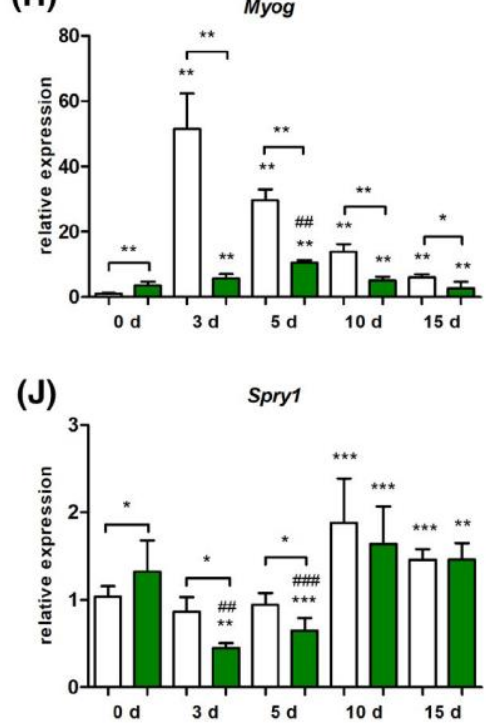
Table 1

\begin{tabular}{|c|c|c|c|c|c|c|c|c|c|c|c|c|c|c|c|c|c|c|c|c|}
\hline & \multirow{3}{*}{$\begin{array}{l}\text { od } \\
\text { wr }\end{array}$} & \multirow[b]{3}{*}{ HTz } & \multirow[b]{3}{*}{ WT } & \multirow[b]{3}{*}{ HTz } & \multicolumn{4}{|l|}{$3 d$} & \multicolumn{4}{|l|}{$5 d$} & \multicolumn{4}{|l|}{$10 \mathrm{~d}$} & \multicolumn{4}{|l|}{$15 \mathrm{~d}$} \\
\hline & & & & & \multicolumn{2}{|l|}{ EI } & \multicolumn{2}{|l|}{ CTX } & \multicolumn{2}{|l|}{ EI } & \multicolumn{2}{|l|}{$\operatorname{crx}$} & \multicolumn{2}{|l|}{ EI } & \multicolumn{2}{|l|}{ cry } & \multicolumn{2}{|l|}{ E } & \multicolumn{2}{|l|}{$\operatorname{cTx}$} \\
\hline & & & & & WT & HTZ & wT & HTZ & wT & Irrz & wr & HTz & WT & HTZ & $\mathbf{w r}$ & HTZ & wr & HTZ & wT & Irrz \\
\hline Necrosis & - & - & - & - & + & + & - & + & - & + & - & - & - & - & - & - & - & - & - & - \\
\hline $\begin{array}{l}\text { Degenerationd } \\
\text { Infil trating alls }\end{array}$ & - & - & - & - & +++ & +++ & ++++ & ++++ & + & +++ & +++ & ++++ & - & + & + & ++ & - & - & - & - \\
\hline Centronucleated fbers & - & - & - & - & - & - & - & - & - & - & - & - & +++ & +++ & +++ & +++ & +++ & +++ & ++++ & +++ \\
\hline
\end{tabular}

